\title{
Neural crest ontogeny during secondary neurulation: a gene expression pattern study in the chick embryo
}

\author{
LILIANA OSÓRIO*,1,2,3, MARIE-AIMÉE TEILLET ${ }^{1,2}$, ISABEL PALMEIRIM ${ }^{3}$ and MARTIN CATALA*,1,2 \\ 1UPMC Univ Paris 06, UMR 7622, Laboratoire de Biologie du Développement, Paris, France, \\ ${ }^{2}$ CNRS, UMR 7622, Laboratoire de Biologie du Développement, Paris, France and \\ ${ }^{3}$ Life and Health Sciences Research Institute, School of Health Sciences, University of Minho, Braga, Portugal
}

\begin{abstract}
In the prospective lumbo-sacral region of the chick embryo, neurulation is achieved by cavitation of the medullary cord, a process called secondary neurulation. Neural crest cells (NCC) are generated in this region and they give rise to the same types of derivatives as in more rostral parts of the trunk where neurulation occurs by dorsal fusion of the neural plate borders (primary neurulation). However, no molecular data were available concerning the different steps of their ontogeny. We thus performed a detailed expression study of molecular players likely to participate in the generation of secondary NCC in chick embryos between Hamburger and Hamilton stages 18-20 (HH18-20) at the level of somites 30 to 43 . We found that specification of secondary NCC involves, as in primary neurulation, the activity of several transcription factors such as Pax3, Pax7, Snail2, FoxD3 and Sox9, which are all expressed in the dorsal secondary neural tube as soon as full cavitation is achieved. Moreover, once specification has occurred, emigration of NCC from the dorsal neuroepithelium starts facing early dissociating somites and involves a series of changes in cell shape and adhesion, as well as interactions with the extracellular matrix. Furthermore, Bmp4 and Wnt1 expression precedes the detection of migratory secondary NCC and is coincident with maturation of adjacent somites. Altogether, this first study of molecular aspects of secondary NCC ontogeny has revealed that the mechanisms of neural crest generation occurring along the trunk region of the chick embryo are generally conserved and independent of the type of neurulation involved.
\end{abstract}

KEY WORDS: epithelium-to-mesenchyme transition, delamination, BMP/WNT signaling

Neurulation, the developmental process leading to the formation of the vertebrate neural tube (NT), classically follows two spatially and temporally distinct processes in amniote embryos. In the anterior part of the body, which corresponds to the cephalic and cervico-thoracic regions, neurulation involves bending of the neural plate, a thickened epithelium that rapidly folds up into a groove, giving rise to a tube by dorsal fusion of its lateral borders. This process, called primary neurulation, ends up as early as 15somite stage (stage 12 of Hamburger and Hamilton (1951) $(\mathrm{HH} 12))$ at the prospective level of the $27^{\text {th }}$ pair of somites, where the posterior neuropore is located in the chick embryo (Schoenwolf, 1979). In contrast, during secondary neurulation, occurring at the level of the presumptive lumbo-sacro-caudal region, formation of the NT occurs by cavitation of a solid rod of cells, the medullary cord (Schoenwolf and Delongo, 1980; Catala et al., 1995). Fate mapping and transplantation experiments have shown that, de- spite the morphological differences which distinguish these two modes of neurulation, the same mechanisms are involved as far as the elongation process of the neural tube is concerned (Catala et al., 1995; Catala et al., 1996; Wilson and Beddington, 1996; Charrier et al., 2005).

We are here focusing on the neural crest (NC), a transient structure appearing in the dorsal NT shortly after its formation, and giving rise to a population of migrating cells that generate a great set of distinct structures according to their origin along the antero-posterior (AP) axis. In the avian embryo, NC cells (NCC)

\footnotetext{
Abbreviations used in this paper: AP, antero-posterior; DSHB, Developmental Study Hybridoma Bank; E, embryonic day; ECM, extracellular matrix; EDS, early dissociating somites; EMT, epithelium-to-mesenchyme transition; HH, Hamburger and Hamilton; NC, neural crest; NCC, neural crest cells; NT, neural tube; PSM, presomitic mesoderm.
}

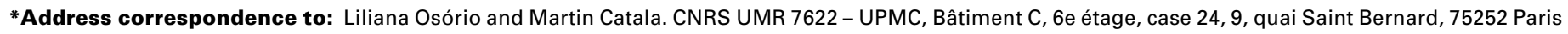
Cedex 05, France.Fax: +33-1-4427-3497.e-mail: liliana.osorio-da-silva@snv.jussieu.fr and mcatala@snv.jussieu.fr - Web: http://bio-dev.snv.jussieu.fr/
} 
arising from the cephalic levels give rise to mesectodermal derivatives (such as skeleton of the face and skull, dermis of the head and neck, connective tissue and tendons of the face and eye muscles, and meninges of the forebrain). They also produce neural and glial derivatives that yield the cephalic peripheral (sensory and parasympathetic) nervous system, and melanocytes. In contrast, at the trunk level, avian NCC do not give rise to mesectodermal derivatives but generate Schwann cells and neurons of the peripheral nervous system (sensory, sympathetic and parasympathetic), medullary cells of the adrenal glands and melanocytes (see Le Douarin and Kalcheim, 1999 for a review). In primary neurulation, the NC primordium corresponds to the border between neural and non-neural ectoderm and then, as neural folds fuse, it becomes located in the dorsal aspect of the NT. Once specified by a distinct program of gene expression, these cells undergo an epithelium-to-mesenchyme transition (EMT), delaminate from the neuroepithelium and migrate into the
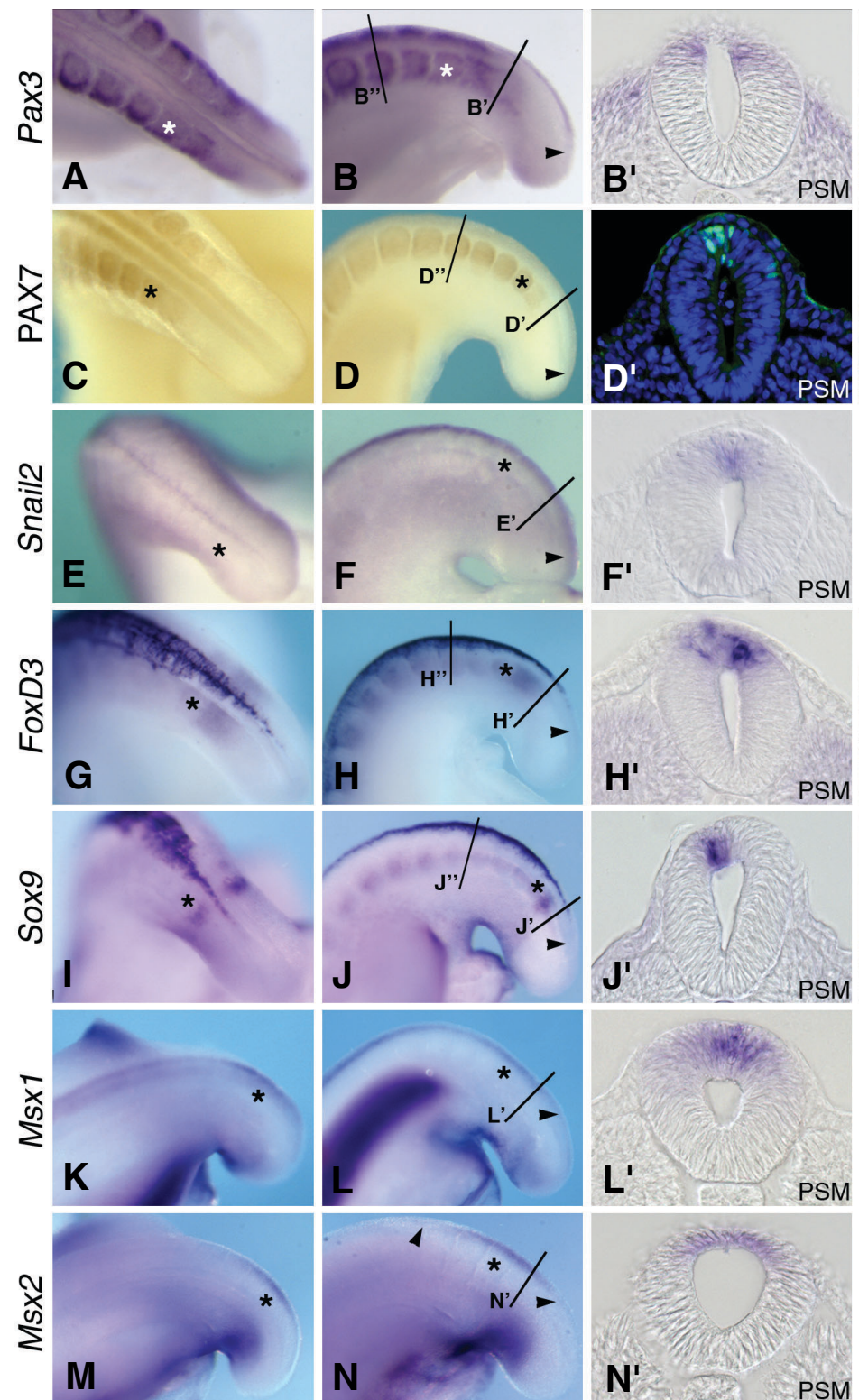
the level of the PSM.
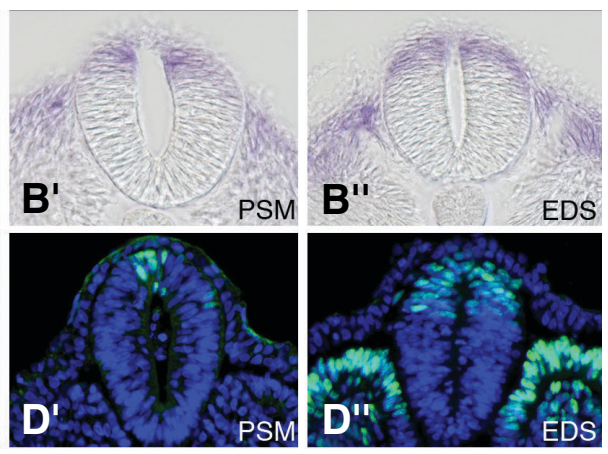

periphery where they differentiate (see Kalcheim and BurstynCohen, 2005 for a review). As a consequence of its proper mode of formation, the dorsal region of the secondary NT is not issued from the fusion of neural folds, but it also gives rise to NCC contributing to the same types of cells as its more rostral trunk counterpart (Schoenwolf et al., 1985; Catala et al., 1995; Catala et al., 2000).

During the last decades, great progresses have been made in the identification of the molecules and mechanisms involved in the different steps leading to the formation of the primary NC. However, generation of NCC from the secondary NT has been the subject of much less analysis and no molecular data are available concerning the several aspects of the formation of these cells. This prompted us to perform, at the level of the secondary neurulation, a detailed study of expression of a large set of molecules known to act in the different steps of NC genesis. Our study was carried out in chick embryos from $\mathrm{HH} 18$ to $\mathrm{HH} 20$, during the $3^{\text {rd }}$ day of embryonic development (E3). From these stages onwards, morphogenesis and growth of the caudal part of the body result from the development of the tail bud, the region located caudally to the posterior neuropore (Schoenwolf, 1979; Catala et al., 1995). We have focused our analysis in the most recently orga-

Fig. 1. Specification of secondary neural crest cells in HH18-20 chick embryos. $(\mathbf{A}, \mathbf{B})$ Pax3 expression in whole mount, dorsal view (A) and lateral view (B). Asterisk indicates the last formed somites and arrowhead points the posterior limit of expression. Cross-sections at the level of presomitic mesoderm (PSM) (B') and early dissociating somites (EDS) (B'"). (C,D) PAX7 immuno-detection in whole mount dorsal (C) and lateral (D) and cryo-sections at the

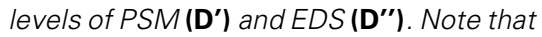
both transcription factors are detected in the dorsal NT soon after its formation facing posterior PSM and persist on migrating NCC close to the dorsal NT. They are also detected in the somite cells $\left(\boldsymbol{B}^{\prime \prime}, \boldsymbol{D}^{\prime \prime}\right)$. (E, $\left.\boldsymbol{F}\right)$ Whole mount expression of Snail2 in dorsal view (E) and lateral view (F). Snail2 is expressed in the dorsal NT from the level of the $9^{\text {th }}-10^{\text {th }}$ last formed somites down to the posterior PSM seen in cross-section $\left(\mathbf{F}^{\prime}\right)$. (G,H) Whole mount in situ hybridiza-

J"
tion for FoxD3 in dorsal (G) and lateral (H) views. Cross-sections at the

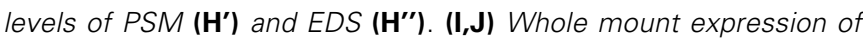
Sox9 in dorsal (I) and lateral (J) views and cross-sections at the levels of PSM ( $\left.\mathbf{J}^{\prime}\right)$ and EDS ( $\left.\mathbf{J}^{\prime \prime}\right)$. FoxD3 and Sox9 are firstly expressed in the dorsal secondary NT facing posterior PSM and their expression persists in more anterior regions. Early migrating NCC located close to the NT are also expressing both of these genes $\left(\mathbf{H}^{\prime \prime}, \mathbf{J} \mathbf{J}^{\prime \prime}\right)$. (K,L) Whole mount Msx1 expression in dorsal (K) and lateral (L) views. (L') Crosssection at the level of anterior PSM. (M,N) Whole mount expression of Msx2 in the dorsal NT from the $4^{\text {th }}$ last formed somite down to the anterior PSM in dorsal (M) and lateral (N) views. (N') Cross-section at 

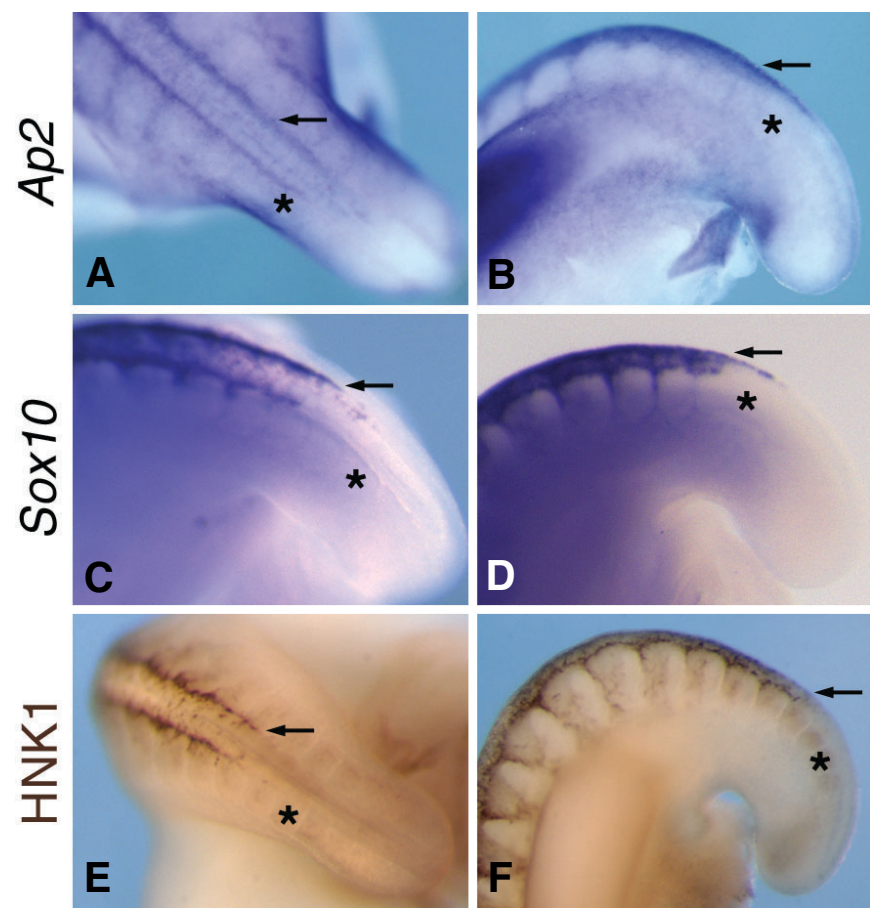

Fig. 2. Early migration of secondary neural crest cells in HH18-20 chick embryos. (A,B) Whole mount in situ hybridization for Ap2 in dorsal (A) and lateral (B) views showing NCC emigrating at the level of the $2^{\text {nd }}$ last formed somite (arrows). (C,D) Whole mount in situ hybridization for Sox10 in dorsal (C) and lateral (D) views, with migrating NCC detected at the level of the $3^{\text {rd }}$ last formed somite (arrows) (E,F) Immuno-detection in whole mount for HNK1 in dorsal (E) and lateral (F) views.

nized region of these embryos corresponding to the level of future somites 30 to 43 , namely the non-segmented area, the last formed epithelial somites and early dissociating somites (EDS), in which one can follow the successive stages of NC maturation along a caudo-rostral direction.

We have analyzed the expression pattern of a great number of transcription factors implicated in the specification of the NC (see Sauka-Spengler and Bronner-Fraser, 2006 for a review). All of them are detected in the dorsal secondary NT a short time after this one is fully formed and they exhibit a differential expression according to the NT state of maturation along its caudo-rostral axis. Genes like Pax3 and $\operatorname{Pax} 7$ (Fig. 1A-D) are detected dorsally in the recently formed NT, soon after cavitation is completed, in a level corresponding to posterior presomitic mesoderm (PSM) (Fig. 1B',D'). More rostrally, their expression continues in the dorsal region of the NT and they are also transiently expressed by NCC that have recently emigrated from the neuroepithelium (Fig. 1B",D"). Snail2 (previously known as Slug) is expressed transiently in the secondary NT, soon after its full cavitation, from the level of posterior PSM (Fig. 1E-F') up to the $9^{\text {th }}-10^{\text {th }}$ last formed somites (not shown). We found that FoxD3 and Sox9 (Fig. 1G-J), considered as the "NC-specifying" genes together with Snail2 (Cheung et al., 2005), are also expressed dorsally in the recently formed secondary NT. However, their first detection in the posterior PSM level is slightly more rostral (Fig. $\left.1 \mathrm{H}^{\prime}, \mathrm{J}^{\prime}\right)$ than that of Pax3, Pax7 and Snail2. Contrarily to this last one, which ends at about the $10^{\text {th }}$ last formed somite, their expression persists more rostrally (not shown). Moreover, they are transiently present in the early migrating NCC located close to the NT (Fig. 1H",J"). In contrast, Msx1 and Msx2 are firstly detected in the dorsal NT located at the level of the anterior PSM (Fig. 1K-N'). Besides, we have found that Msx1 persists in the more rostral NT (Fig. 1L), while Msx2 is only detected transiently, disappearing at the level of the $4^{\text {th }}$ last formed somite (Fig. $1 \mathrm{~N}$ ).

Once they are specified, emigrating NCC acquire specific markers. The first of them, Ap2, is detected in the dorsal NT at the level of the anterior PSM like the markers of NC specification (Fig. $2 \mathrm{~A}-\mathrm{B}$ ) and it persists in the NCC that have recently emigrated from the neuroepithelium at the level of the $2^{\text {nd }}$ last formed somite (Fig. $2 \mathrm{~A}, \mathrm{~B}$ ). Other markers, such as Sox 10 and HNK1, label migratory secondary NCC somewhat later. While Sox10 appears at the level of the $3^{\text {rd }}$ last formed somite (Fig. 2C,D), HNK1 is apparent at the transition between the $3^{\text {rd }}$ and $4^{\text {th }}$ last formed somite (Fig. $2 \mathrm{E}, \mathrm{F})$. In sum, although $A p 2$ and other markers of early migration (such as Pax3, Pax7, FoxD3 and Sox9) show secondary NCC emigrating in front of the $2^{\text {nd }}$ last formed somite, other markers like HNK1 give results similar to that reported in primary neurulation regions: in 15 to 25 -somite stage ( $\mathrm{HH} 11$ to $\mathrm{HH} 15)$ chick embryos, onset of NCC migration occurs at the level of the $3^{\text {rd }}-4^{\text {th }}$ last formed somites (Tosney, 1978; Thiery et al., 1982; Teillet et al., 1987).

We have then examined the delamination of secondary NCC, a process that involves, in the cervico-thoracic region, a series of cellular events that are similar to those occurring in any EMT (see Duband, 2006 for a review). We have observed that $R$ hoB, a small GTPase proposed to control cell adhesion and motility (Liu and Jessel, 1998), is detected along the entire length of the secondary NT (Fig. 3B), in a dorso-ventral gradient (Fig. 3A), which is visible

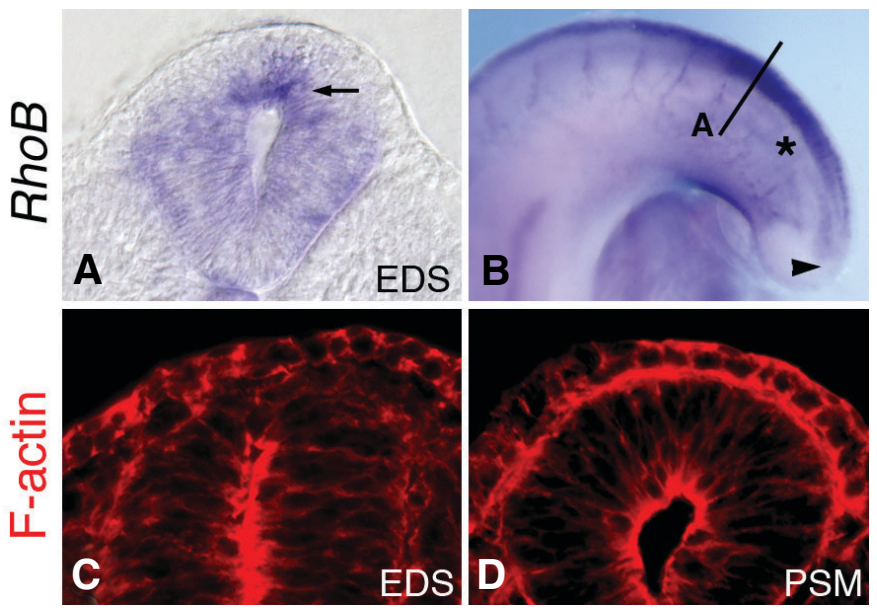

Fig. 3. RhoB expression and cell shape changes during epitheliumto-mesenchyme transition of secondary neural crest cells in HH1820 chick embryos. (A,B) In situ hybridization for RhoB in cross-section at the level of early dissociating somites (EDS) and whole mount. This small GTPase is expressed in a dorso-ventral gradient (A) along the entire length of secondary neural tube (NT) (B). Note the polarized distribution of the transcripts in the apical side of the dorsal neuroepithelial cells (arrow). Asterisk points to the last somite formed and arrowhead points the posterior limit of expression. (C) During emigration of NCC at the level of EDS, phalloidin immunolabeling shows a loss of accumulation of $F$ actin in the apical side of the cells of the dorsal NT. (D) Before onset of NCC emigration at the level of presomitic mesoderm (PSM), these cells exhibit the typical apico-basal polarity of neuroepithelial cells. 

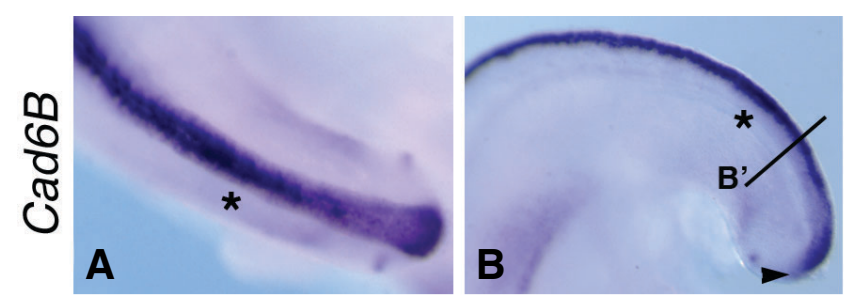
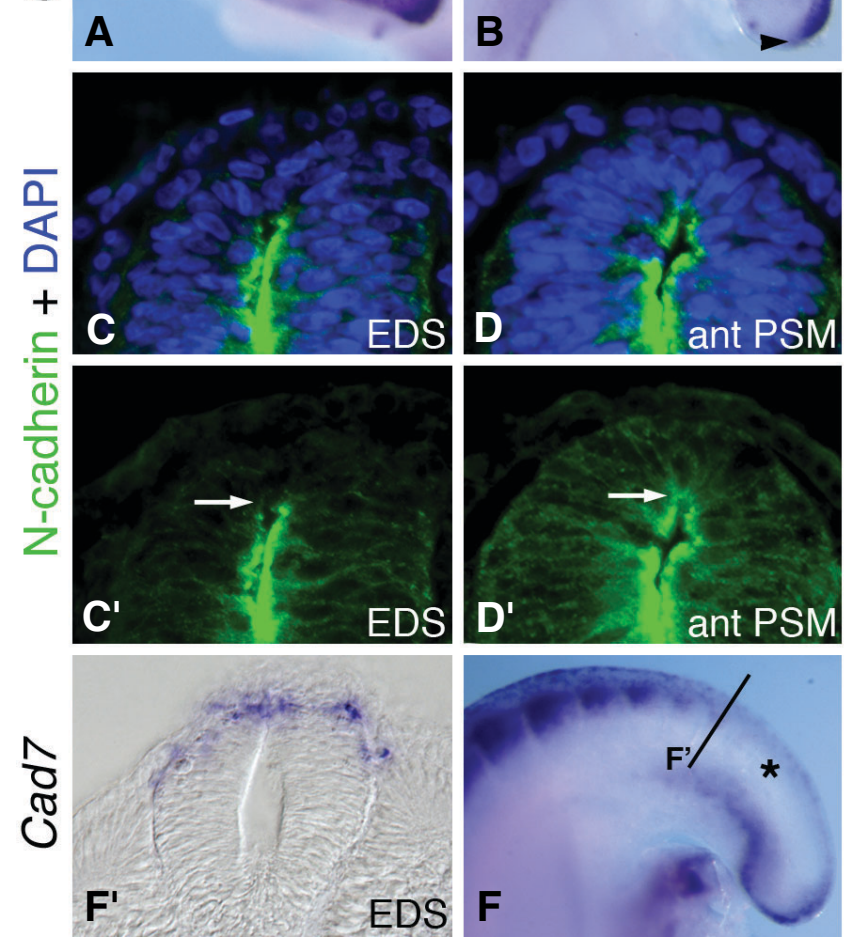

B'
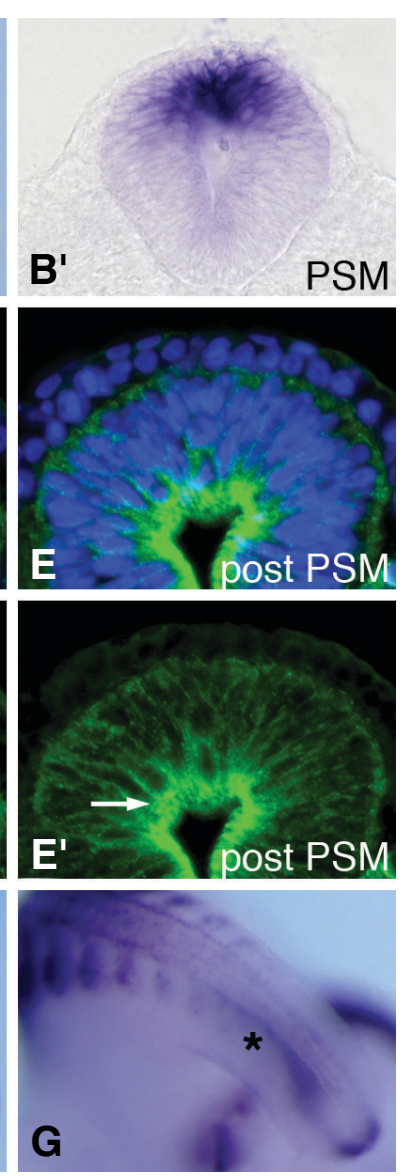

Fig. 4. Differential cadherin expression during epithelium-to-mesenchyme transition of secondary neural crest cells in HH18-20 chick embryos. (A,B) Expression of Cad6B all along the secondary neural tube (NT) down to the tail bud detected by whole mount in situ hybridization in dorsal (A) and lateral (B) views. (B') Cross-section at the level of the presomitic mesoderm (PSM) showing that this gene is expressed in the dorsal region of the NT. Asterisk represents the last formed somite and arrowhead points the posterior limit of expression. (C-E') Immuno-detection of $\mathrm{N}$-cadherin on cryo-sections, counterstained with DAPI (C-E). The accumulation of $\mathrm{N}$-cadherin in the dorsal cells of the secondary NT at the posterior PSM level $\left(\mathbf{E}, \mathbf{E}^{\prime}\right)$ is progressively decreased in the anterior PSM (D, $\left.\mathbf{D}^{\prime}\right)$ and in early dissociating somite (EDS) (C,C') levels. Arrows point the decreased apical accumulation of $\mathrm{N}$-cadherin on dorsal cells of the secondary NT as this one maturates ( $\left.\mathbf{C}^{\prime}-\mathbf{E}^{\prime}\right)$. ( $\mathbf{F}^{\prime}$-G) Once migrating, secondary NCC express Cad7, detected by in situ hybridization in cross-section at the level of EDS (F') and in whole mount lateral (F) and dorsal (G) views. soon after NT formation at a level facing the posterior PSM (not shown). Moreover, we have evidenced that $R$ hoB expression is polarized in the dorsal cells of the NT facing EDS, where transcripts are accumulated in their apical side (Fig. 3A). Emigrating secondary NCC do not express RhoB (not shown). This pattern of expression of $R h o B$ is quite different from that described in more anterior regions at equivalent stage. For example, it has been shown that, in 10-somite stage $(\mathrm{HH} 10)$ chick embryos, this molecule is initially expressed in the dorsal tips of the neural folds, dorsal NT and transiently in migrating NCC located close to the NT (Liu and Jessel, 1998). To determine if the differences that we have ascertained are due to different staining methodology, we have analyzed $R h o B$ expression during primary neurulation in 17- to 18-somite stage embryos (HH12-13) and we have obtained results similar to that of Liu and Jessel (1998) (not shown). Thus, RhoB is differently expressed during primary and secondary neurulation. Since it is assumed that this molecule participates in EMT of NCC through dynamic regulation of actin cytoskeleton (Liu and Jessel, 1998), we decided to analyze the distribution of F-actin in the context of secondary neurulation. We have found that Factin is accumulated both in the basal and in the apical sides of the dorsal cells of the secondary NT before onset of migration of the NCC at the level of PSM (Fig. 3D). Once migration starts at the level of EDS, the basal accumulation of F-actin is lost whereas the apical one continues to be observed (Fig. 3C). Thus, the reorganization of the actin cytoskeleton, contributing to the cell shape changes that precede emigration of NCC (Newgreen and Minichiello, 1996), is similar in secondary and primary neurulation regions, although the distinct pattern of expression of $R h o B$, proposed to control actin cytoskeleton (Liu and Jessell, 1998), in these two regions.

We have also observed signs of significant changes in the cellular adhesion of dorsal cells of secondary NT. Long before NCC emigration, the dorsal cells of the secondary NT express Cad6B (Fig. 4A,B'). Moreover, N-cadherin, present in the dorsal cells of the secondary NT located at the level of the posterior PSM (Fig. 4E,E'), progressively disappears from these cells, before and during NCC emigration as seen respectively at anterior PSM (Fig. 4D,D') and EDS (Fig. 4C,C') levels. Once migrating, secondary NCC, first seen at the level of $3^{\text {rd }}$ last formed somite, express Cad7 (Fig. 4F-G').

We have ascertained the status of several extracellular matrix (ECM) components during generation of secondary NCC. As shown by laminin immuno-detection, the basement membrane of the secondary NT is partially absent (dotted interruptions) in the dorsal portion of the secondary NT since its formation at the level of the posterior PSM (Fig. 5B). This lack of a complete basement membrane persists during emigration of NCC (Fig. 5A). In contrast, concomitantly with the dorsal interruption of the basal lamina, we have observed that two main components of the fibrillar ECM, fibronectin and tenascinC, are present all around the secondary NT and along the migratory pathways of the NCC before (Fig. 5D,F) and during (Fig. 
$5 \mathrm{C}, \mathrm{E}$ ) emigration of these cells. Coincident with the changes in both the cell shape (see Figure 3 ) and adhesion (see figure 4), we have observed that the distribution of TASC, the activated form of beta1-integrin, is also modified as emigration of secondary NCC occurs. At the level of the PSM, we have found that TASC has a polarized distribution in the basal side of the dorsal cells of the secondary NT (Fig. $5 \mathrm{H}$ ). Loss of this basal accumulation is observed as emigration of NCC starts at the level of EDS (Fig. 5G). Altogether, our observations show that delamination of secondary NCC involves the same cellular events that those occurring during emigration of NCC at the level of primary neurulation.

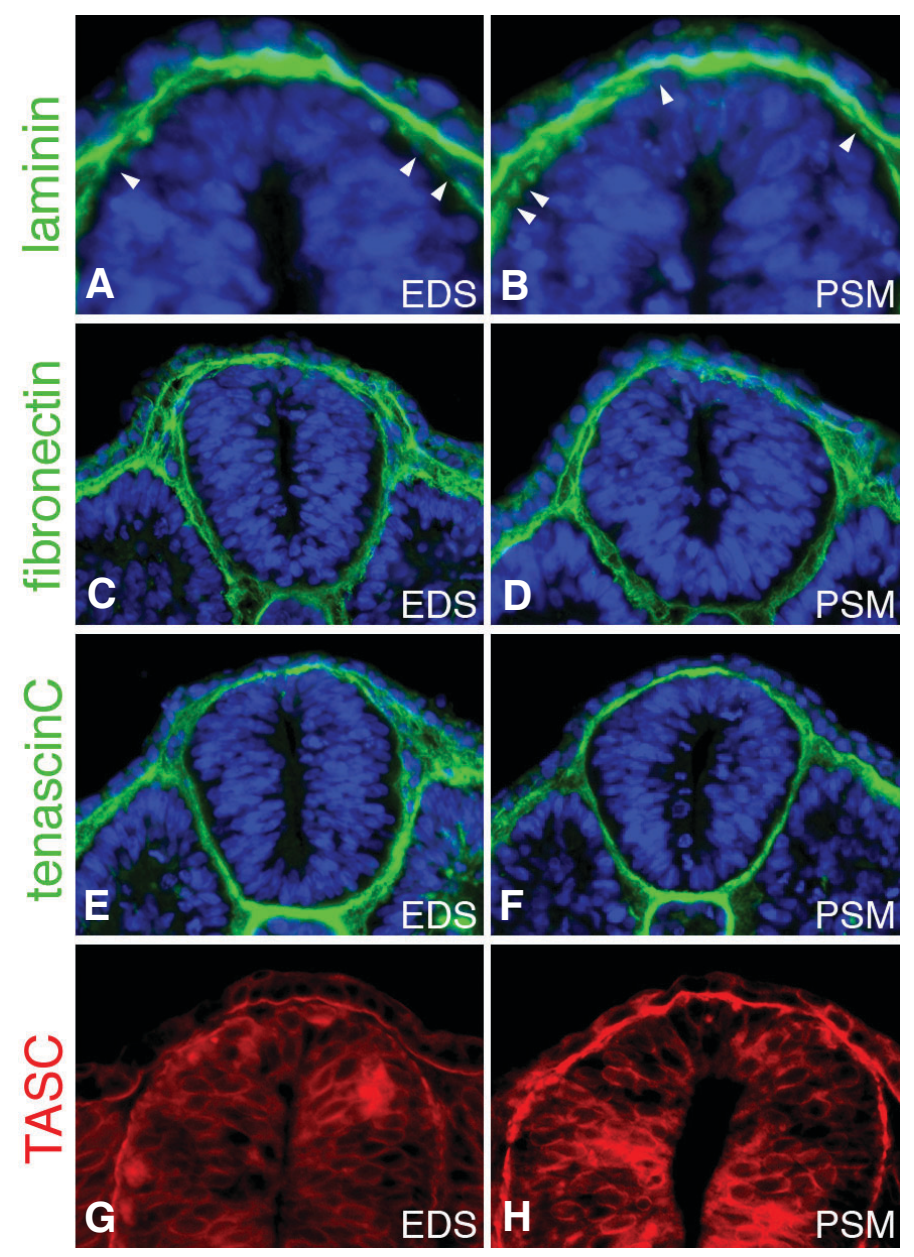

Fig. 5. Properties of the extracellular matrix during epithelium-tomesenchyme transition of secondary neural crest cells in HH18-20 chick embryos. $(\mathbf{A}, \mathbf{B})$ Laminin immuno-detection on cryo-setions at the levels of presomitic mesoderm (PSM) (B) and early dissociating somites (EDS) (A). Basement membrane of the dorsal secondary neural tube (NT) is not complete both before (B) and during (A) emigration of neural crest cells (NCC) (arrowheads). (C-F) Immuno-fluorescence for fibronectin $(\mathbf{C}, \mathbf{D})$ and tenascinC $(\mathbf{E}, \mathbf{F})$ on cryo-sections, showing that both of these molecules are present in the extracellular matrix surrounding the secondary NT and along the migration pathways of NCC before (D,F) and during (C,E) emigration of these cells. (G,H) TASC, the activated form of beta1-integrin detected by immuno-histochemistry on cryo-sections, presents a polarized distribution in the apical side of the cells of the dorsal secondary early NT (H) that is lost as migration of NCC occurs (G)
Additionally to an EMT, onset of trunk NCC migration normally requires a BMP-dependent of WNT activity (SelaDonenfeld and Kalcheim, 1999; Sela-Donenfeld and Kalcheim, 2000; Burstyn-Cohen et al., 2004; Shoval et al., 2007). We have thus continued our study about the molecular aspects of generation of secondary NCC by analysis of such pathways. Bmp4 is expressed in the secondary dorsal NT along a rostro-caudal gradient that vanishes at the level of the posterior PSM (Fig. 6AB"). Moreover, one of its inhibitors, Noggin, has a complementary pattern of expression (Fig. 6C-D"), being detected in the recently formed dorsal NT, from the level of the posterior PSM (Fig. 6D") up to the $1^{\text {st }}-2^{\text {nd }}$ last formed somites (Fig. 6C-D). Noggin is no longer detected as somites dissociate (Fig. 6D') and this is coincident with the detection of migratory NCC (see figure 2). Furthermore, we observed that expression of Wnt1 in the dorsal secondary NT starts at the level of the $1^{\text {st }}-2^{\text {nd }}$ last formed somite (Fig. 6F') where Noggin is no longer detected (Fig. 6D'). Wnt1 expression persists in more anterior regions (Fig. 6E,F). As in primary neurulation (Burstyn-Cohen et al., 2004), down-regulation of Noggin, coincident with the initiation of Wnt 1 expression, slightly precedes emigration of secondary NCC.

In the present study, we have described the different steps involved in the generation of the secondary NCC in the lumbosacral region, at the level of somites 30 to 43 , in the chick embryo. Several transcription factors that have been implicated in the specification of the trunk NCC are expressed in the dorsal region of the secondary NT shortly after its formation (full cavitation). Genes like Pax3, Pax7 and Snail2 are detected early at the level of the posterior PSM, while others (such as Msx1 and Msx2) are detected later at the anterior PSM level. Moreover, once specification of secondary NCC has occurred, emigration of these cells from the neuroepithelium starts facing EDS. Secondary NCC delamination involves a series of cellular events, such as reorganization of the F-actin cytoskeleton that contributes to changes in the shape of the premigratory cells. Furthermore, a dynamic regulation of the adhesion of secondary NCC was also observed, as shown by the differential expression of $\mathrm{Cad6B}, \mathrm{N}$-cadherin and $\mathrm{Cad} 7$ by these cells. All these changes are accompanied by a modification of interaction with the components of the ECM, as demonstrated by the distribution of TASC in the dorsal cells of the secondary NT. In addition, we have shown that the acquisition of motility by secondary NCC is coincident with an increased activity of $B m p 4$, through both an increase in the proper transcripts as well as down-regulation of its inhibitor Noggin, and de novo expression of Wnt1. These events are related with the maturation of the adjacent somites, since migratory NCC are firstly detected at the level of early dissociating somites. Altogether, our work points out for the first time the molecular aspects of the different steps involved in the formation of secondary NCC. In addition, a careful comparison of the onset of expression of the several genes analysed allows us to propose a molecular hierarchy operating during ontogeny of secondary NC (Fig. 7). The analysis of the great set of molecules that we have performed suggests that the molecular code and mechanisms acting in the different stages of NC generation are similar along the trunk axis in the chick embryo, independently of the type of neurulation that leads to the formation of the NT. However, our results 

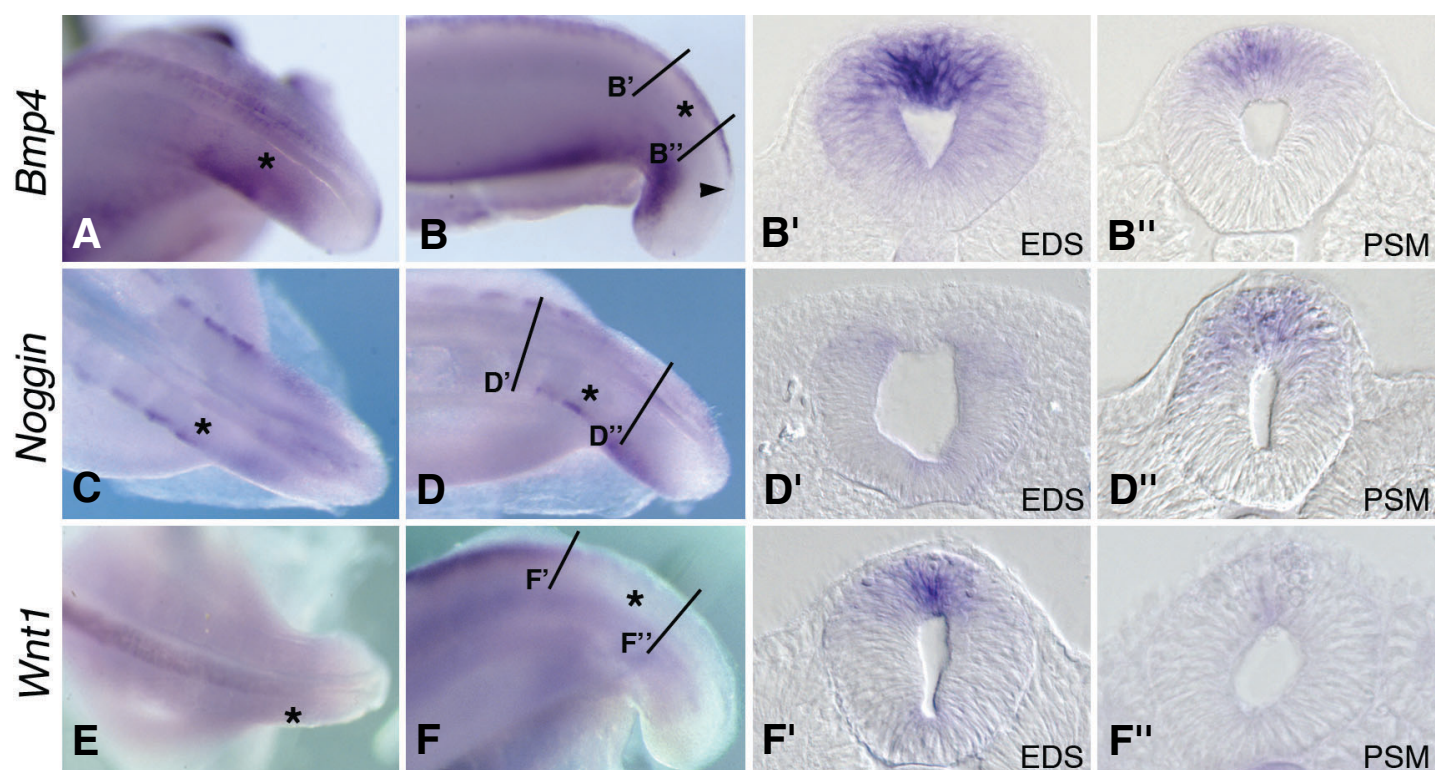

Fig. 6. Secondary neural crest cell migration follows BMP and WNT signaling in $\mathrm{HH} 18$ 20 chick embryos. In situ hybridization of Bmp4 (A,B), Noggin $\mathbf{( C , D )}$ and Wnt1 (E,F) in whole mount embryos in dorsal $(\mathbf{A}, \mathbf{C}, \mathbf{E})$ and lateral $(\mathbf{B}, \mathbf{D}, \mathbf{F})$ views, and cross-sections at the levels of the early dissociating somites (EDS) ( $\left.\mathbf{B}^{\prime}, \mathbf{D}^{\prime}, \mathbf{F}^{\prime}\right)$ and presomitic mesoderm (PSM) (B", D", $\left.\mathbf{F}^{\prime \prime}\right)$. Asterisks indicate the last formed somite and arrowhead points the posterior limit of expression. Note that Bmp4 and Noggin are ex-

pressed in a complementary rostro-caudal gradient along the dorsal secondary neural tube (NT). Bmp4 is detected down to the level of posterior PSM, (A-B'), while Noggin is detected facing posterior PSM and down-regulated at the level of the $1^{\text {st }}-2^{\text {nd }}$ last formed somites (C-D"). Increase in Bmp4 activity is accompanied by the expression of Wnt1 that persists in the dorsal NT in more anterior regions (E-F").

also put forward several differences relative to generation of $\mathrm{NC}$ in the head. These include variations in the onset of expression of genes such as Pax3, Snail2 and RhoB. In the cephalic region, Snail2 precedes the expression of Pax3 (del Barrio and Nieto, 2002) and $R h o B$ is present in a small population of Snail2-expressing cells (del Barrio and Nieto, 2004). We have found that during secondary neurulation, onset of $P a x 3$ and Snail2 expression in the dorsal aspect of the secondary NT are concomitant, with $R h o B$ being detected earlier than these two transcription factors. Furthermore, $C a d 6 B$ is quickly down-regulated in the head by Snail2 (del Barrio and Nieto, 2002; Coles et al., 2007) while it is maintained in the secondary NT after onset of
NCC emigration (this study). Moreover, the mechanisms triggering NCC delamination are also different in the head and trunk regions. In both primary and secondary trunk NT, emigration of NCC from the neuroepithelium involves a $\mathrm{Bmp} 4$ activity regulated by a gradient of Noggin expression in the dorsal NT (SelaDonenfeld and Kalcheim, 1999; this study). In contrast, typical delamination of NCC in the head region involves the activity of Snail2 and Ets1 (Theveneau et al., 2007) and not that of Bmp4. Thus, our results about formation of secondary NCC emphasize some differences in the development of $\mathrm{NC}$ in the cephalic versus trunk region. However, along the trunk, despite the obvious morphological differences between primary and secondary neu-

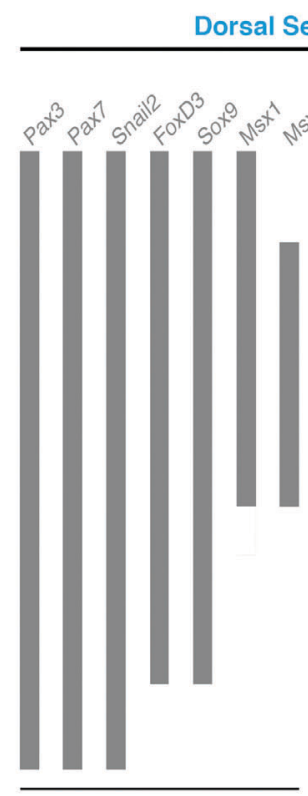

NC specification

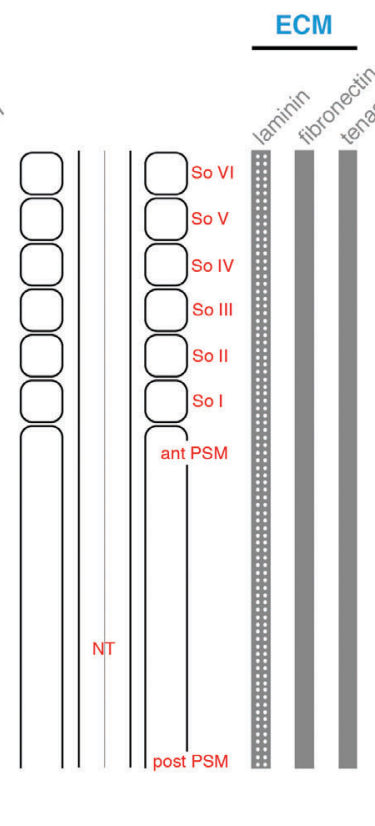

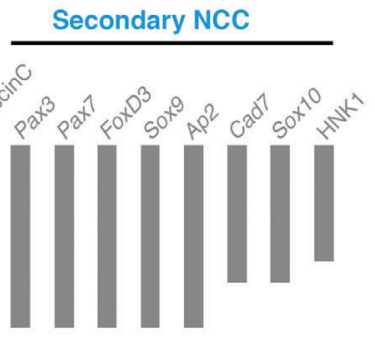

Fig. 7. Comparative molecular expression during secondary neural crest genesis. The neural tube (NT), presomitic mesoderm (PSM) and the 6 last formed somites (So I to VI) are schematized in the middle of the figure. Vertical bars indicate the anterior and posterior limits of gene expression in accordance with the state of maturation of the paraxial mesoderm. The expression patterns of the genes present in the dorsal secondary NT are on the left side, while those occurring in the extracellular matrix (ECM) and migratory secondary neural crest cells (NCC) are on the right side. Striped bars represent a polarized basal expression in the dorsal cells of the NT. Dotted bar represents the incomplete accumulation of laminin around the dorsal aspect of the secondary NT. 
rulation, identical mechanisms are implicated in NC formation.

\section{Materials and Methods}

\section{Chick and quail embryos}

Fertilized chick (Gallus gallus domesticus) eggs of commercial sources were incubated at $38^{\circ} \mathrm{C}$ in humidified atmosphere. Embryos were staged according to Hamburger and Hamilton $(\mathrm{HH})$ table (1951) and/or referred to embryonic day (E). Control and experimental embryos were fixed in $4 \%$ paraformaldehyde either 2 hours at room temperature (RT) for immunohistochemistry, or overnight $(\mathrm{ON})$ at $4^{\circ} \mathrm{C}$ for in situ hybridization. For tissue sections, fixed embryos were cryo-protected in $15 \%$ sucrose ON at $4^{\circ} \mathrm{C}$, embedded in gelatin, frozen and conserved at $-20^{\circ} \mathrm{C}$. Serial 8,12 or $30 \mu \mathrm{m}$ sections were performed in a Leica cryostat and mounted on glass slides.

\section{In situ hybridization in whole embryos and sections}

Whole mount in situ hybridizations were performed according to Henrique and collaborators (1995) with the following chick-specific riboprobes: Ap2 (Shen et al., 1997), Bmp4 (Francis-West et al., 1994), Cad6B and Cad7 (Nakagawa and Takeichi, 1995), FoxD3 (Dottori et al., 2001; Kos et al., 2001), Msx1 (Coelho et al., 1992) and Msx2 (Coelho et al., 1991), Noggin (Reshef et al., 1998), Pax3 (Goulding et al., 1993), RhoB (Liu and Jessel, 1998), Snail2 (Nieto et al., 1994), Sox9 (Cheung and Briscoe, 2003), Sox10 (Cheng et al., 2000) and Wnt1 (Megason and McMahon, 2002). Once photographed, embryos were processed for cryo-sectioning as previously described.

\section{Immunohistochemistry in whole embryos and sections}

Immunohistochemistry was performed as previously described (Afonso and Catala, 2005) using the following primary antibodies: anti- $\mathrm{N}$-cadherin 1:500 (FA-5, Sigma), anti-fibronectin 1:200 (Rovasio et al., 1983; kindly provided by Dr. Jean-Loup Duband), anti-activated beta1-integrin (TASC) 1:100 (MAB19294, Chemicon), anti-laminin 1:100 (L9393, Sigma), antiNC1/HNK1 1:20 (Vincent et al., 1983; Vincent and Thierry, 1984; Tucker et al., 1984; kindly provided by Dr. Jean-Loup Duband), anti-PAX7 1:20 (Developmental Study Hybridoma Bank, (DSHB)), anti-tenascinC 1:300 (AB19013, Chemicon). For whole mount immunohistochemistry, species-specific secondary antibodies were conjugated with HRP (1:100, Southern Biotechnologies). Once photographed, embryos were processed for cryo-sectioning as previously described. For immunofluorescence in sections we used secondary antibodies conjugated with FITC or TRITC (1:200, Southern Biotechnologies). For F-actin labeling, we have used phalloidin conjugated with TRITC 1:1000 (P1951, Sigma). DAPI 1:5000 (D1306, Molecular Probes) for counterstaining.

\section{Acknowledgments}

We are grateful to our colleagues for helpful discussions. We thank $\mathrm{Dr}$ Jean-Loup Duband for fibronectin and NC1 antibodies and Dr James Briscoe for Sox9 plasmid. This work has been supported by Centre National de la Recherche Scientifique (CNRS), University Paris 6 (UPMC), Fundação para Ciência e Tecnologia (FCT), Association Française contre les Myopathies (AFM). LO is a recipient of a grant from FCT (SFRH/BD/11858/2003).

\section{References}

AFONSO, N.D. and CATALA, M. (2005). Sonic hedgehog and retinoic acid are not sufficient to induce motoneuron generation in the avian caudal neural tube. Dev Biol 279: 356-67.

BURSTYN-COHEN, T., STANLEIGH, J., SELA-DONENFELD, D. and KALCHEIM, C. (2004). Canonical Wnt activity regulates trunk neural crest delamination linking BMP/noggin signaling with G1/S transition. Development 131: 5327-39.

CATALA, M., TEILLET, M.A., DE ROBERTIS, E.M. and LE DOUARIN, M.L. (1996).
A spinal cord fate map in the avian embryo: while regressing, Hensen's node lays down the notochord and floor plate thus joining the spinal cord lateral walls. Development 122: 2599-610.

CATAlA, M., TEILLET, M.A. and LE DOUARIN, N.M. (1995). Organization and development of the tail bud analyzed with the quail-chick chimaera system. Mech Dev 51: 51-65.

CATALA, M., ZILLER, C., LAPOINTE, F. and LE DOUARIN, N.M. (2000). The developmental potentials of the caudalmost part of the neural crest are restricted to melanocytes and glia. Mech Dev 95: 77-87.

CHARRIER, J.B., CATALA, M., LAPOINTE, F., LE-DOUARIN, N. and TEILLET, M.A. (2005). Cellular dynamics and molecular control of the development of organizer-derived cells in quail-chick chimeras. Int J Dev Biol 49: 181-91.

CHENG, Y., CHEUNG, M., ABU-ELMAGD, M.M., ORME, A. and SCOTTING, P.J. (2000). Chick sox10, a transcription factor expressed in both early neural crest cells and central nervous system. Brain Res Dev Brain Res 121: 233-41.

CHEUNG, M. and BRISCOE, J. (2003). Neural crest development is regulated by the transcription factor Sox9. Development 130: 5681-93.

CHEUNG, M., CHABOISSIER, M.C., MYNETT, A., HIRST, E., SCHEDL, A. and BRISCOE, J. (2005). The transcriptional control of trunk neural crest induction, survival, and delamination. Dev Cell 8: 179-92.

COELHO, C.N., SUMOY, L., KOSHER, R.A. and UPHOLT, W.B. (1992). GHox-7: a chicken homeobox-containing gene expressed in a fashion consistent with a role in patterning events during embryonic chick limb development. Differentiation 49: 85-92.

COELHO, C.N., SUMOY, L., RODGERS, B.J., DAVIDSON, D.R., HILL, R.E., UPHOLT, W.B. and KOSHER, R.A. (1991). Expression of the chicken homeoboxcontaining gene GHox-8 during embryonic chick limb development. Mech Dev 34: 143-54.

COLES, E.G., TANEYHILL, L.A. and BRONNER-FRASER, M. (2007). A critical role for Cadherin6B in regulating avian neural crest emigration. Dev Biol 312: 53344.

DEL BARRIO, M.G. and NIETO, M.A. (2002). Overexpression of Snail family members highlights their ability to promote chick neural crest formation. Development 129: 1583-93

DEL BARRIO, M.G. and NIETO, M.A. (2004). Relative expression of Slug, RhoB, and HNK-1 in the cranial neural crest of the early chicken embryo. Dev Dyn229: 136-9.

DOTTORI, M., GROSS, M.K., LABOSKY, P. and GOULDING, M. (2001). The winged-helix transcription factor Foxd3 suppresses interneuron differentiation and promotes neural crest cell fate. Development 128: 4127-38.

DUBAND, J.L. (2006). Neural crest delamination and migration: integrating regulations of cell interactions, locomotion, survival and fate. Adv Exp Med Biol 589: 45-77.

FRANCIS-WEST, P.H., TATLA, T. and BRICKELL, P.M. (1994). Expression patterns of the bone morphogenetic protein genes Bmp-4 and Bmp-2 in the developing chick face suggest a role in outgrowth of the primordia. Dev Dyn201: 168-78.

GOULDING, M.D., LUMSDEN, A. and GRUSS, P. (1993). Signals from the notochord and floor plate regulate the region-specific expression of two Pax genes in the developing spinal cord. Development 117: 1001-16.

HAMBURGER, V. and HAMILTON, H.L. (1951). A series of normal stages in the development of the chick. J Morphol 88: 49-92.

HENRIQUE, D., ADAM, J., MYAT, A., CHITNIS, A., LEWIS, J. and ISH-HOROWICZ, D. (1995). Expression of a Delta homologue in prospective neurons in the chick. Nature 375: 787-90.

KALCHEIM, C. and BURSTYN-COHEN, T. (2005). Early stages of neural crest ontogeny: formation and regulation of cell delamination. Int J Dev Biol 49: 10516.

KOS, R., REEDY, M.V., JOHNSON, R.L. and ERICKSON, C.A. (2001). The winged-helix transcription factor FoxD3 is important for establishing the neural crest lineage and repressing melanogenesis in avian embryos. Development 128: 1467-79.

LE DOUARIN, N.M. and KALCHEIM, C. (1999). The Neural Crest. Cambridge University Press, Cambridge.

LIU, J.P. and JESSELL, T.M. (1998). A role for rhoB in the delamination of neural 
crest cells from the dorsal neural tube. Development 125: 5055-67.

MEGASON, S.G. and MCMAHON, A.P. (2002). A mitogen gradient of dorsal midline Wnts organizes growth in the CNS. Development 129: 2087-98.

NAKAGAWA, S. and TAKEICHI, M. (1995). Neural crest cell-cell adhesion controlled by sequential and subpopulation-specific expression of novel cadherins. Development 121: 1321-32.

NEWGREEN, D.F. and MINICHIELLO, J. (1996). Control of epithelio-mesenchymal transformation. II. Cross-modulation of cell adhesion and cytoskeletal systems in embryonic neural cells. Dev Biol 176: 300-12.

NIETO, M.A., SARGENT, M.G., WILKINSON, D.G. and COOKE, J. (1994). Control of cell behavior during vertebrate development by Slug, a zinc finger gene. Science 264: 835-9.

RESHEF, R., MAROTO, M. and LASSAR, A.B. (1998). Regulation of dorsal somitic cell fates: BMPs and Noggin control the timing and pattern of myogenic regulator expression. Genes Dev 12: 290-303.

ROVASIO, R.A., DELOUVEE, A., YAMADA, K.M., TIMPL, R. and THIERY, J.P. (1983). Neural crest cell migration: requirements for exogenous fibronectin and high cell density. J Cell Biol 96, 462-73.

SAUKA-SPENGLER, T., MEULEMANS, D., JONES, M. and BRONNER-FRASER, M. (2007). Ancient evolutionary origin of the neural crest gene regulatory network. Dev Cell 13: 405-20.

SCHOENWOLF, G.C. (1979). Observations on closure of the neuropores in the chick embryo. Am J Anat 155: 445-65.

SCHOENWOLF, G.C., CHANDLER, N.B. and SMITH, J.L. (1985). Analysis of the origins and early fates of neural crest cells in caudal regions of avian embryos. Dev Biol 110: 467-79.

SCHOENWOLF, G.C. and DELONGO, J. (1980). Ultrastructure of secondary neurulation in the chick embryo. Am J Anat 158: 43-63.

SELA-DONENFELD, D. and KALCHEIM, C. (1999). Regulation of the onset of neural crest migration by coordinated activity of BMP4 and Noggin in the dorsal neural tube. Development 126: 4749-62.
SELA-DONENFELD, D. and KALCHEIM, C. (2000). Inhibition of noggin expression in the dorsal neural tube by somitogenesis: a mechanism for coordinating the timing of neural crest emigration. Development 127: 4845-54.

SHEN, H., WILKE, T., ASHIQUE, A.M., NARVEY, M., ZERUCHA, T., SAVINO, E., WILLIAMS, T. and RICHMAN, J.M. (1997). Chicken transcription factor AP-2: cloning, expression and its role in outgrowth of facial prominences and limb buds. Dev Biol 188: 248-66.

SHOVAL, I., LUDWIG, A. and KALCHEIM, C. (2007). Antagonistic roles of fulllength $\mathrm{N}$-cadherin and its soluble BMP cleavage product in neural crest delamination. Development 134: 491-501.

TEILLET, M.A., KALCHEIM, C. and LE DOUARIN, N.M. (1987). Formation of the dorsal root ganglia in the avian embryo: segmental origin and migratory behavior of neural crest progenitor cells. Dev Biol 120: 329-47.

THEVENEAU, E., DUBAND, J.L. and ALTABEF, M. (2007). Ets-1 confers cranial features on neural crest delamination. PLOS ONE 2: e1142.

THIERY, J. P., DUBAND, J.L. and DELOUVE, A. (1982). Pathways and mechanisms of avian trunk neural crest cell migration and localization. Dev Biol 93, 324-43.

TOSNEY, K. W. (1978). The early migration of neural crest cells in the trunk region of the avian embryo: an electron microscopic study. Dev Biol 62, 317-33.

TUCKER, G.C., AOYAMA, H., LIPINSKI, M., TURSZ, T. and THIERY, J.P. (1984). Identical reactivity of monoclonal antibodies HNK1 and NC1: conservation in vertebrates on cells derived from the neural primordium and on some leukocytes. Cell Differ 14, 223-30.

VINCENT, M. and THIERY, J.P (1984). A cell surface marker for neural crest and placodal cells: further evolution in peripheral and central nervous system. Dev Biol 103, 468-81.

VINCENT, M., DUBAND, J.L. and THIERY, J.P (1983). A cell surface determinant expressed early on migrating avian neural crest cells. Brain Res 285, 235-8.

WILSON, V. and BEDDINGTON, R. S. (1996). Cell fate and morphogenetic movement in the late mouse primitive streak. Mech Dev 55, 79-89. 


\section{Further Related Reading, published previously in the Int. J. Dev. Biol.}

See our Special Issue Invasion, edited by Marc Mareel and Juan Aréchaga at:

http://www.ijdb.ehu.es/web/contents.php?vol=52\&issue=5-6

See our Special Issue The Nogent Institute, in honor of Nicole Le Douarin and edited by Francoise Dieterlen at: http://www.ijdb.ehu.es/web/contents.php?vol=48\&issue=5-6

Pax7 identifies neural crest, chromatophore lineages and pigment stem cells during zebrafish development Ana M Lacosta, Jesús Canudas, Cristina González, Pedro Muniesa, Manuel Sarasa and Luis Domínguez Int. J. Dev. Biol. (2007) 51: 327-331

Fate of cranial neural crest cells during craniofacial development in endothelin-A receptor-deficient mice Makoto Abe, Louis-Bruno Ruest and David E. Clouthier Int. J. Dev. Biol. (2007) 51: 97-105

Msx1 and Msx2 have shared essential functions in neural crest but may be dispensable in epidermis and axis formation in Xenopus

Deepak Khadka, Ting Luo and Thomas D. Sargent

Int. J. Dev. Biol. (2006) 50: 499-502

Neural crest derivatives in ocular and periocular structures

Sophie Creuzet, Christine Vincent and Gérard Couly

Int. J. Dev. Biol. (2005) 49: 161-171

Early stages of neural crest ontogeny: formation and regulation of cell delamination Chaya Kalcheim and Tal Burstyn-Cohen

Int. J. Dev. Biol. (2005) 49: 105-116

The instability of the neural crest phenotypes: Schwann cells can differentiate into myofibroblasts

Carla Real, Corinne Glavieux-Pardanaud, Pierre Vaigot, Nicole Le Douarin and Elisabeth Dupin

Int. J. Dev. Biol. (2005) 49: 151-159

Migration of neural crest-derived enteric nervous system precursor cells to and within the gastrointestinal tract

Alan J. Burns

Int. J. Dev. Biol. (2005) 49: 143-150

Origins and plasticity of neural crest cells and their roles in jaw and craniofacial evolution.

Paul A Trainor, Kristin R Melton and Miguel Manzanares

Int. J. Dev. Biol. (2003) 47: 541-553

Cell-intrinsic and cell-extrinsic cues regulating lineage decisions in multipotent neural crest-derived progenitor cells.

Christian Paratore, Lilian Hagedorn, Julien Floris, Lisette Hari, Maurice Kléber, Ueli Suter and Lukas Sommer

Int. J. Dev. Biol. (2002) 46: 193-200

Patterns of migration and regulation of trunk neural crest cells in zebrafish (Danio rerio).

$\mathrm{J} \mathrm{L}$ Vaglia and $\mathrm{B} \mathrm{K}$ Hall

Int. J. Dev. Biol. (2000) 44: 867-881
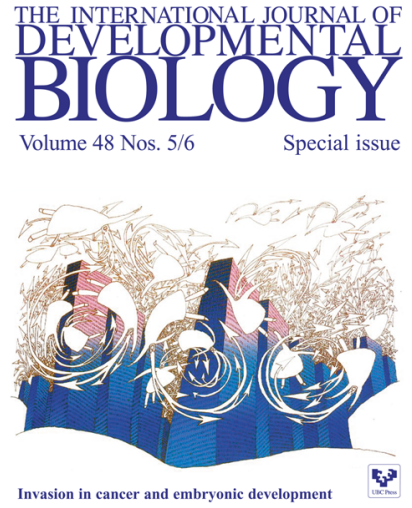

2006 ISI **Impact Factor $=3.577^{* *}$

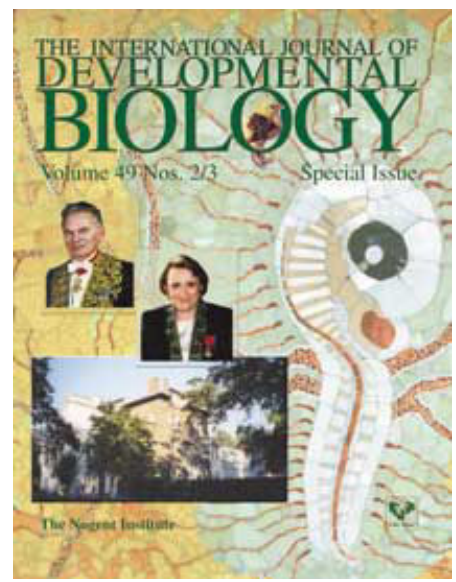

